\title{
Формирование современной системы регионального и муниципального управления 1
}

\begin{abstract}
A.C. НОВОСЕЛОВ, доктор экономических наук, E-mail: asnov@ieie.nsc.ru А.С. МАРШАЛОВА, кандидат экономических наук, Институт экономики и организации промышленного производства СО РАН, Новосибирск. E-mail: marnov@ieie.nsc.ru
\end{abstract}

Аннотация. В статье проводится анализ действующей системы регионального и муниципального управления с целью выявления проблем, которые она не в состоянии решить или решает не в полной мере. Отмечается, что современное социально-экономическое развитие России сопровождается высокой пространственной дифференциацией регионов и муниципальных образований, при этом региональная экономическая политика и институциональные механизмы её реализации не учитывают региональных особенностей, многоукладности экономики и особой роли пространственного фактора в достижении высоких темпов социально-экономического развития. Показано, что на протяжении многих лет система управления демонстрирует свою неспособность обеспечить реализацию периодически формулируемых стратегических целей развития экономики и региональной политики. Доказательством неэффективности этой системы является невыполнение намеченных планов и приоритетов. Предложены меры по совершенствованию институциональной системы управления, направленные на улучшение инвестиционного климата, модернизацию экономики, рост уровня жизни населения регионов и муниципальных образований и повышение эффективности регионального и муниципального управления.

Ключевые слова: региональное и муниципальное управление; институциональная система управления; пространственная дифференциация; региональная экономическая политика; экономический механизм; эффективность управления

Наряду с сырьевой ориентацией, технологической отсталостью и крайне низкой долей наукоемкого производства, к наиболее трудно разрешимым проблемам российской экономики относится чрезвычайно высокая региональная дифференциация социально-экономического развития [Лексин, 2017; Минакир, 2018].

\footnotetext{
${ }^{1}$ Исследование выполнено в рамках государственного задания по проекту XI.173.1.2. «Стратегическое управление региональным и муниципальным развитием: концепция и принципы реализации» № AАAА-A17-117022250118-6.
} 
Нельзя не учитывать, что проблемы пространственного развития России в значительной степени порождены объективными обстоятельствами:

- страна занимает первое место в мире по территории, при этом значительная ее часть находится за полярным кругом;

- динамика численности населения и других демографических факторов не соответствует территориальным масштабам страны;

- исторически сложившаяся структура расселения отличается неравномерностью; в Сибири и на Дальнем Востоке - крайне низкая плотность населения;

- сложившиеся в последние годы отчетливые тенденции центростремительной миграции, интенсивной урбанизации еще больше осложняют поддержание целостности экономического пространства.

Эффективная региональная политика призвана сглаживать эти противоречия, обеспечивая равные возможности и доступ к основным благам всем жителям страны. Но в России пока это удается плохо, о чем красноречиво свидетельствуют данные таблицы, в которой приведены индексы дифференциации некоторых макроэкономических показателей по субъектам Федерации. Каждый федеральный округ представлен в ней двумя регионами, максимально различающимися по удельному ВРП (для большей наглядности). Интегральным индикатором уровня социальноэкономического развития регионов может служить темп роста численности населения: в относительно благополучных регионах численность растет (или, по крайней мере, не падает), в депрессивных - сокращается. Исключение составляют республики Северо-Кавказского федерального округа, для которых характерна высокая рождаемость.

Расчетные индексы свидетельствуют о том, что среднедушевой ВРП в Москве в 2,43 раза превышает общероссийский показатель, а в соседней Ивановской области составляет всего 0,36 от среднего по стране. Среднедушевые доходы в Москве почти вдвое выше среднероссийских, в Ивановской области - всего 0,77. Сравнительный индекс среднемесячной зарплаты в Москве $(1,84)$ в 3,1 раза превышает этот же показатель в Ивановской 
области $(0,60)$, при этом прожиточный минимум в этих регионах различается всего лишь в 1,6 раза $^{2}$.

\section{Сравнительный уровень некоторых основных макроэко- номических показателей по регионам России в 2017 г. (в расчете на душу населения), ед.}

\begin{tabular}{|l|c|c|c|c|c|}
\hline \multicolumn{1}{|c|}{ Субъект РФ } & ВРП & $\begin{array}{c}\text { Среднедуше- } \\
\text { вые доходы }\end{array}$ & $\begin{array}{c}\text { Средне- } \\
\text { месячная } \\
\text { зарплата }\end{array}$ & $\begin{array}{c}\text { Инвес- } \\
\text { тиции }\end{array}$ & $\begin{array}{c}\text { Изменение числен- } \\
\text { ности населения } \\
\text { за 2006-2017 гг. }\end{array}$ \\
\hline Российская Федерация & 1,00 & 1,00 & 1,00 & 1,00 & 1,03 \\
\hline Москва & 2,43 & 1,92 & 1,84 & 1,20 & 1,38 \\
\hline Санкт-Петербург & 1,28 & 1,34 & 1,33 & 0,88 & 1,11 \\
\hline Ивановская область & 0,36 & 0,77 & 0,60 & 0,25 & 0,93 \\
\hline Московская область & 0,93 & 1,31 & 1,13 & 0,81 & 1,09 \\
\hline Псковская область & 0,43 & 0,72 & 0,61 & 0,49 & 0,89 \\
\hline Республика Калмыкия & 0,37 & 0,47 & 0,58 & 0,54 & 0,95 \\
\hline Краснодарский край & 0,78 & 1,07 & 0,78 & 1,43 & 1,09 \\
\hline Республика Дагестан & 0,48 & 0,92 & 0,61 & 0,65 & 1,13 \\
\hline Республика Ингушетия & 0,21 & 0,49 & 0,56 & 0,36 & 1,15 \\
\hline Республика Мордовия & 0,53 & 0,58 & 0,35 & 0,72 & 0,94 \\
\hline Самарская область & 0,85 & 0,87 & 0,77 & 0,88 & 0,99 \\
\hline Курганская область & 0,46 & 0,66 & 0,64 & 0,41 & 0,88 \\
\hline Ямало-Ненецкий округ & 7,44 & 2,19 & 2,27 & 1,46 & 1,04 \\
\hline Республика Тыва & 0,33 & 0,48 & 0,81 & 0,40 & 1,04 \\
\hline Новосибирская область & 0,76 & 0,83 & 0,82 & 0,69 & 1,04 \\
\hline $\begin{array}{l}\text { Еврейская автономная } \\
\text { область }\end{array}$ & 0,59 & 0,77 & 0,96 & 0,31 & 0,90 \\
\hline $\begin{array}{l}\text { Чукотский автономный } \\
\text { округ }\end{array}$ & 3,73 & 2,08 & 2,36 & 1,31 & 0,96 \\
\hline
\end{tabular}

Источник: Регионы России. Социально-экономические показатели. 2017: Стат. сб. / Росстат. М., 2017.1402 с.

Сохраняющаяся дифференциация по индексу среднедушевых инвестиций (за 2010-2017 гг. в Москве этот показатель в 1,2 раза превысил общероссийский уровень, а в Республике Ингушетия составил лишь 0,36 ) только усугубляет негативные тенденции. Причем, неравномерность в пространственном распределении отмечается даже для государственных инвестиций: в общей величине капвложений доля бюджетных средств, которые приходятся только на три субъекта Федерации - Москву, Санкт-Петербург 
и Московскую область, составляет $27 \%{ }^{3}$. То есть почти треть своих инвестиций государство направляет в те регионы, которые, в отличие от многих других, способны привлекать частный капитал. Вряд ли такой подход может способствовать выравниванию пространственных различий.

Проведенные исследования показывают, что сохранение сложившихся тенденций отрицательно скажется на общем экономическом развитии страны и ее социальной стабильности [Минакир, 2018; Стратегическое управление.., 2018].

Достоверность статистики, безусловно, является необходимым элементом объективной оценки текущего состояния социально-экономического развития страны и ее регионов, так как именно институт статистической службы создает информационную основу для принятия планово-прогнозных решений [Кисельников, 2017]. К сожалению, содержательный анализ ряда статистических показателей свидетельствует о том, что они могут служить основанием лишь для иллюзорной картины пространственного развития.

Так, например, высокий душевой ВРП в Москве дает повод столичным чиновникам, включая главу города С. Собянина, утверждать, что и производительность труда в Москве в два раза выше, чем в других регионах. Более того, на этом основании мэр даже делает вывод о перенаселенности Подмосковья, по какой-то причине упуская из виду, что значительная часть его жителей работает в столице, своим трудом наполняя ее бюджет. При этом известно, что в структуре занятости Москвы, как и любого мегаполиса, около 70\% составляют служащие госуправления, финансово-кредитной системы, сферы операций с недвижимостью, торговли, транспорта, гостиничного и коммунального хозяйства; в реальном секторе экономики - в промышленности и строительстве - занято не более $24 \%$ работающих (по состоянию на 2016 г.). На самом деле высокие показатели «производительности» объясняются тем, что в Москве зарегистрирована

\footnotetext{
${ }^{3}$ Тенденция стягивания государственных инвестиций на территорию, прилегающую к Москве, продолжается: еще в 2014 г. Правительство РФ приняло решение о выделении значительных государственных средств на строительство третьего транспортного кольца. Между тем московская агломерация имеет наиболее благоприятный инвестиционный климат и более привлекательна для частных инвестиций по сравнению с большинством других регионов России. Поэтому, с точки зрения интересов государства, вместо того, чтобы использовать бюджетные ресурсы, было бы целесообразно и вполне реально привлечь к этому строительству частных инвесторов.
} 
подавляющая часть головных офисов крупнейших государственных корпораций, сосредоточены активы почти всей банковской сферы России.

Как показывает практика, простая территориальная перерегистрация крупной госкорпорации в другом регионе вызывает радикальные пространственные изменения в формировании бюджетной системы страны ${ }^{4}$. При этом в ее экономике ровным счетом ничего не меняется.

Если верить российской статистике, Москва обеспечивает $60 \%$ всего российского экспорта топливно-энергетических ресурсов, тогда как совместный вклад Ханты-Мансийского и Ямало-Ненецкого округов составляет только 5,8\%. Этот экспорт и вошел в валовой региональный продукт Москвы как продукция «Газпрома», «Роснефти» и других топливно-энергетических компаний со столичной пропиской. При таком «достоверном» отражении экономики главной информационно-статистической системой России дать реальную оценку пространственного развития страны, экономической структуры и эффективности ее регионов не представляется возможным.

Известно, что решением проблем пространственного развития СССР в условиях планово-распределительной системы занимался Совет по развитию производительных сил (СОПС). В основе пространственной политики страны лежали такие факторы, как размещение сырьевой базы, потребности в продукции отраслей и др. Анализ этих факторов, а также оценка всей совокупности экономико-географических и социальных условий определяли Схему развития и размещения производительных сил страны и, соответственно, специализацию регионов, структуру их экономики и общие параметры развития.

Одним из важнейших принципов государственной пространственной политики было продвижение производительных сил на Восток. Ее зримыми результатами стало создание в Восточной Сибири мощной гидроэнергетики и развитие энергоемких производств, формирование крупнейшего Западносибирского

\footnotetext{
${ }^{4}$ Очевидным абсурдом действующего законодательства является возможность регистрации головного офиса компании на территории, не имеющей ни малейшего отношения к ее производственной деятельности. Учитывая объективно необоснованную практику, по-видимому, было бы целесообразно закрепить налог на прибыль крупных государственных компаний полностью за федеральным уровнем. В этом случае у них не возникнет желания к перемене места регистрации, и, соответственно, не возникнет угроза для устойчивости региональных бюджетов.
} 
нефтегазового комплекса. При этом следует отметить, что и в советские времена для регионов страны были характерны серьезные различия в уровне социально-экономического развития [Гранберг, 2009].

\section{Формирование институциональной системы управления пространственным развитием}

Сегодня гипертрофированная дифференциация в уровне социально-экономического развития российских регионов настолько бросается в глаза, что игнорировать ее становится невозможно. Пространственные различия подрывают идею единого социально-экономического пространства страны и создают реальную угрозу национальной безопасности. Полагать, что эти проблемы могут решаться с помощью только рыночных механизмов, было бы наивно ${ }^{5}$. Рациональное пространственное развитие страны как фактор национальной безопасности является непосредственной функцией государственного управления.

Наличие комплекса нерешенных проблем в социально-экономическом развитии регионов и муниципальных образований нашей страны красноречиво свидетельствует о неэффективности действующей системы управления на всех ее уровнях - от федерального до муниципального. А поступательное нарастание этих проблем требует скорейших изменений этой системы и формирования таких институциональных структур, которые бы адекватно отражали цели социально-экономического развития регионов и муниципальных образований и были бы способны обеспечить их реализацию.

Нельзя сказать, что федеральные власти не понимают актуальности этой задачи, но пока их попытки создания новых институтов управления, способных активизировать экономическое развитие регионов, трудно назвать удачными. Здесь следует отметить двуединую функцию государства в условиях господства рыночных отношений: с одной стороны, она состоит

\footnotetext{
${ }^{5}$ Анализ опыта пространственного развития зарубежных стран показывает, что ориентация экономики исключительно на рыночные силы приводила к неравномерности размещения населения и производства и возникновению региональных диспропорций. Поэтому экономические механизмы управления развитых стран все больше дополняются специальными административными инструментами (предварительная государственная экспертиза инвестиционных проектов, перераспределение доходов регионов через механизм государственного бюджета и т.д.), направленных на сглаживание пространственных различий [Казакова, Климанов, 2018, Bennett, 2012, McGrath, 2013, Seltzer, Carbonell, 2011, Wolfe,2013].
} 
в поддержке конкурентной среды и, следовательно, в широком использовании рыночных механизмов. С другой - заключается в ограничении этих механизмов в целом ряде сфер деятельности, к числу которых относятся, например, сохранение национальной безопасности, социальной стабильности, а также гармоничное пространственное развитие страны.

К сожалению, создание новых федеральных структур, призванных представлять интересы государственного управления на территориях, зачастую носит бессистемный рефлексивный характер. Первыми, как известно, были федеральные округа и институт полномочных представителей Президента в этих округах 6 . Затем последовала череда формального упразднения отдельных министерств и их возрождение под новым названием. Так, Министерство РФ по делам Федерации и национальностей было сначала преобразовано в Министерство региональной политики, затем в Министерство по делам Федерации, национальной и миграционной политики, а впоследствии - в Министерство регионального развития РФ. Никакого ощутимого влияния на региональное развитие ни одна из этих структур не оказала из-за отсутствия у них финансовых средств: основные бюджетные ресурсы концентрируются в Министерстве финансов РФ и Министерстве экономического развития РФ, которые крайне неохотно делятся своими полномочиями. Более того, дублирование полномочий и функций реализации государственной пространственной политики, сосредоточенных в Минфине РФ, Минэкономразвития РФ и других, нередко вызывает межведомственные противоречия, неопределенность приоритетов и приводит к неэффективному использованию бюджетных средств. [Климанов и др., 2017].

Начиная с 2014 г. появилась практика создания специальных институтов управления развитием отдельных территорий. Были сформированы федеральные министерства по делам развития Дальнего Востока, Северного Кавказа, Крыма и Севастополя,

\footnotetext{
${ }^{6}$ В 2000 г. было сформировано семь федеральных округов: Центральный, Северо-Западный, Южный, Приволжский, Уральский, Сибирский, Дальневосточный, в 2010 г. из их состава был выделен восьмой - Северо-Кавказский ФО. В 2018 г. два субъекта Федерации (Республика Бурятия и Забайкальский край) были выведены из состава Сибири и вошли в состав Дальневосточного ФО. Основные управленческие функции полпредов - координация деятельности федеральных органов исполнительной власти в соответствующем округе, организация их взаимодействия с органами власти регионов и органами местного самоуправления; разработка программ и стратегий социальноэкономического развития территорий в пределах федерального округа и др.
} 
государственная комиссия по вопросам развития Арктики, органы управления особыми экономическими зонами, территориями опережающего развития. На них возлагались задачи, связанные с развитием экономики территорий, сокращения региональной дифференциации в уровне и качестве жизни, повышения эффективности использования ресурсного потенциала регионов и реализации их конкурентных преимуществ. К сожалению, поставленные задачи не были подкреплены соответствующими бюджетными ресурсами.

Апофеозом многолетних поисков новых институциональных управленческих решений и путей решения проблем пространственного развития страны стала бесплатная раздача дальневосточного гектара всем желающим.

Такие бессистемные поиски и административные реформы могут продолжаться еще долго [Клименко, 2014]. Между тем мировой опыт показывает, что для успеха такого рода преобразований необходимо прежде всего решить фундаментальные вопросы и обосновать методологические принципы управления: что должна представлять собой новая модель пространственного развития страны, какова должна быть роль государства в экономике регионов и как должны распределяться полномочия между различными уровнями системы управления (федеральным, региональным, муниципальным)? И далее - каковы принципы формирования финансово-бюджетных потоков и их соответствие полномочиям и ответственности каждого уровня системы управления?

\section{Планово-прогнозные разработки как основа управления и необходимость повышения их качества (несколько примеров)}

На начальном этапе становления новой модели экономического развития страны наивно полагалось, что все сложнейшие процессы в экономике будут регулироваться рынком, который лучше «знает», что и где производить. Полная деградация экономики и социальной сферы заставила отказаться от столь примитивных представлений и попытаться адаптировать к закономерностям развития многоукладной экономики прежнюю планово-прогнозную систему. Переход к индикативному планированию стал первым 
прорывом в этом направлении․ Было признано, что макроэкономические индексы, как сигнальные лампочки, подтверждают движение социально-экономических процессов в нужном направлении. При этом генеральным целевым показателем был провозглашен индекс инфляции ${ }^{8}$.

Важными элементами системы институционального управления являются законодательно-правовые нормы и планово-прогнозные документы, в которых рассматриваются стратегические направления развития регионов и управленческие механизмы, обеспечивающие их реализацию.

В 2014 г. был принят федеральный закон № 172-Ф3 «О стратегическом планировании...», направленный на повышение эффективности всех уровней системы управления, который уже на этапе обсуждения его научно-экспертным сообществом обнаружил ряд разночтений и несоответствий с ранее утвержденными нормативными актами 9

К сожалению, диспут вокруг законопроекта связан главным образом с правовыми несоответствиями и не отражает содержательные социально-экономические аспекты регулируемых им стратегических планово-прогнозных документов. Между тем конкретное наполнение этих документов заслуживает самого пристального внимания и обсуждения.

Например, в части разработки стратегий развития муниципальных образований необходимо четко определить, для каких муниципальных образований она целесообразна, кто должен ею заниматься (представители местных сообществ или субъектов Федерации), какова должна быть информационная база для оценки конкурентных преимуществ территории. Не получили

\footnotetext{
${ }^{7}$ Федеральный закон «О государственном прогнозировании и программах социальноэкономического развития Российской Федерации» от 20 июля 1995 г. № 115-Ф3; Постановление Правительства РФ «О порядке разработки прогноза социально-экономического развития Российской Федерации» от 22 июля 2009 г. № 596.

${ }^{8}$ В настоящее время в экспертном сообществе нет единства в понимании того, насколько адекватно показатель уровня инфляции интегрирует в себе цели, ограничения и возможности развития экономики. Тем не менее в сценариях долгосрочного развития России, разработанных Минэкономразвития РФ, снижение уровня инфляции, сокращение государственных бюджетных расходов сохраняются в качестве базовых ориентиров.

${ }^{9}$ Подробный перечень вопросов и рассогласований, возникающих в связи с применением Ф3 «О стратегическом планировании...», был сформирован участниками ХІІІ Общероссийского Форума «Стратегическое планирование в регионах и городах России: обновление стратегий, обновление смыслов» (2014 г.). Замечания варьировали от серьезных опасений по поводу негативных последствий его применения, сформулированных Мау В.А., до предложения Городецкого В. Ф. начать работать по Закону, а корректировки вносить в процессе практической реализации [Победин, 2014].
} 
должного внимания в планово-прогнозных разработках и многие концептуальные вопросы планирования и управления социальноэкономическим развитием на региональном уровне, хотя в экономической литературе по ним не раз высказывались конкретные предложения [Климанов, Сафина, 2017].

Для создания основы практического использования закона 172-Ф3 в 2017 г. был принят Указ Президента «Основы государственной политики регионального развития РФ на период до 2025 года», в котором были определены правовые принципы государственной политики регионального развития. Они включают в себя обеспечение территориальной целостности, единство правового и экономического пространства России, равных возможностей для реализации прав и свобод граждан, разграничение полномочий между территориальными уровнями власти.

Кроме того, в соответствии с названным законом в 2018 г. была разработана Стратегия пространственного развития $\boldsymbol{P \Phi}$ до 2025 z. $^{10}$ В констатирующей части документа вполне справедливо отмечается, что изменения в схеме расселения граждан РФ отражают общемировые тенденции роста крупных и крупнейших агломераций. Однако это сходство не должно никого успокаивать. Нужно учитывать, что Россия обладает самой большой в мире территорией с самым большим количеством пахотных земель и самой протяженной сухопутной границей. Кроме того, главной причиной центростремительного оттока населения из российских регионов является крайне высокая дифференциация в уровне и качестве жизни. Она же таит в себе серьезную угрозу социального взрыва, который пока не происходит во многом «благодаря» действию внешнеполитических факторов и продолжающимся санкциям.

Некоторые оптимистичные выводы Стратегии о сокращении региональных диспропорций вызывают большие сомнения, как и вышеупомянутые показатели официальной статистики, которые

\footnotetext{
${ }^{10}$ Периодически государственные ведомства формулировали основные направления государственной региональной политики и стратегии развития-ее цели, приоритеты и задачи. Так, еще в 2007 г. была принята «Концепция стратегии социально-экономического развития регионов РФ», разработанная Минрегионразвития РФ. Ее главными приоритетами были формирование из «регионов - локомотивов роста» нового опорного каркаса страны; создание условий для развития конкурентоспособных производственных (территориальных) кластеров и др. Одним из приоритетов новой Стратегии пространственного развития называется сокращение чрезмерной дифференциации в уровне социально-экономического развития регионов. Вместе с тем анализ практики и результатов реализации региональной политики в нашей стране свидетельствует о том, что ни одна из вышеуказанных концепций не находит своего практического воплощения.
} 
должны использоваться в прогнозировании и давать объективную оценку современного состояния уровня социально-экономического развития регионов. Складывается впечатление, что авторы документа не знакомы с реальной ситуацией в регионах России.

По сути, факт региональной дифференциации лишь констатируется как одна из особенностей пространственного развития, характерная для многих развитых стран ${ }^{11}$, при этом о разнице в уровне инвестиций, финансовых, бюджетных аспектах региональных различий даже не упоминается. Между тем 90\% регионов России - дотационные, у них, по определению, отсутствует бюджет развития, зато (в отличие от Москвы и Санкт-Петербурга) они вынуждены нести тяжелое бремя по финансовой поддержке бюджетов сельских муниципальных образований. Примечательно, что последние, также оставаясь глубоко дотационными, не только кормят население страны, но еще и производят экспортную продовольственную продукцию, объем которой (в 2018 г. - 24,9 млрд долл.) $)^{12}$ сопоставим со стоимостью экспорта ВПК (15 млрд долл.) $)^{13}$.

Говоря в Стратегии о государственно-частном партнерстве, следовало бы четко определить, что имеется в виду. Известно, что финансовые ресурсы в России концентрируются в трех основных центрах - это государственный бюджет, банки и топливно-энергетические корпорации, цели которых имеют мало общего. Так, банки больше всего «заинтересованы» в постоянных колебаниях курса валют, топливно-энергетические корпорации - в высоких ценах на нефть и газ на мировом рынке, государственный бюджет - в соблюдении баланса по доходам и расходам. Никто из них не ставит своим приоритетом, к примеру, развитие современного отечественного машиностроения, высоких технологий, потому что это связано с большими финансовыми рисками.

В Стратегии имеется сильный перекос в сторону развития крупных городов и агломераций и, на наш взгляд, недостаточно внимания уделено развитию малых городов и сельских районов, а также вопросам сокращения неоправданно высокой

\footnotetext{
${ }^{11}$ URL: Распоряжение Правительства РФ от 13.02.2019 № 207-р «Об утверждении Стратегии пространственного развития Российской Федерации на период до 2025 года». URL: http://government. $\mathrm{ru} / \mathrm{docs} / 35733 /$

12 Внешняя торговля России в 2018 г. URL: http://russian-trade.com/reports-and-reviews/2019-02/ vneshnyaya-torgovlya-rossii-v-2018-godu/

${ }^{13}$ Россия выполнила план по экспорту оружия на 2018 г. URL: https://ria.ru/20190128/1550004524.html
} 
социально-экономической дифференциации между городскими и сельскими территориями.

Механизм реализации Стратегии сводится к общим рекомендациям, источники финансирования предусмотренных мероприятий не названы, то есть документ носит в основном декларативный характер, предпосылок к повышению качества планово-прогнозных документов и совершенствованию системы управления пространственным развитием России в нем не просматривается.

Стратегия устойчивого развития сельских территорий была принята в 2015 г. $^{14}$ По замыслу разработчиков, ее реализация должна привести к «...стабильному повышению качества и уровня жизни сельского населения на основе преимуществ сельского образа жизни, что позволит сохранить социальный и экономический потенциал сельских территорий и обеспечит выполнение ими общенациональных функций - производственных, демографических» и др.

К сожалению, и этот стратегический документ отличает формальный, схоластический подход. Его адресат неизвестен, кто и каким образом должен воплотить в жизнь его положения непонятно. В Стратегии справедливо отмечается высокая дифференциация в уровне и качестве жизни городского и сельского населения, что создает угрозу продовольственной и социальной безопасности. В то же время при характеристике развития социальной инфраструктуры в сельской местности в тексте обнаруживаются внутренние противоречия.

Так, в разделе «Общие положения» речь идет об успехах, достигнутых в сфере развития образовательных и медицинских учреждений, а в разделе «Качество жизни сельского населения» говорится о том, что количество школ сократилось на 12 тыс., а фельдшерско-акушерских пунктов - на 22\% (при этом периоды, в течение которых все это происходило, указаны неопределенно).

В разделе «Местное самоуправление» отмечается: «как показывает мировой опыт, наличие института местного самоуправления обеспечивает условия для саморазвития населения», но не упоминается, что российский опыт введения этого

\footnotetext{
${ }^{14}$ Распоряжение Правительства РФ от 02.02.2015 № 151-р (ред. от 13.01.2017) «Об утверждении Стратегии устойчивого развития сельских территорий Российской Федерации на период до 2030 года». URL: http://government.ru/docs/16757/
} 
института дискредитирует саму идею самоуправления, так как полномочия, функции и ответственность, которыми законодатели наделили сельские территории, не соответствуют финансовоэкономическим возможностям большинства из них. В разделах, посвященных развитию экономики, ничего не говорится о том, что большинство сельских территорий характеризуется неблагоприятным инвестиционным климатом; когда же речь заходит о финансовых ресурсах, все сводится только к доступности кредитных средств (при этом «доступность» понимается в узком смысле - как высокие кредитные ставки; вопросы кредитоспособности потенциальных заемщиков, неготовности банковской системы финансировать низкорентабельные проекты в зоне рискованного земледелия и т.д. не рассматриваются).

В числе проблем, препятствующих устойчивому развитию сельских территорий, в документе перечисляются широко известные и лежащие на поверхности - неразвитость инфраструктуры, недоступность ресурсов развития, неполноценность системы местного самоуправления, низкое качество уровня жизни, утрата традиционных навыков к сельскохозяйственному труду. В то же время глубинные, фундаментальные проблемы, без решения которых не могут быть решены вышеназванные, даже не упоминаются. К числу последних относятся, например, такие как приоритет отраслевого подхода в государственном управлении, нерешенность проблемы сочетания отраслевых (корпоративных) и территориальных интересов.

Набор целевых показателей устойчивого развития сельских территорий, включая их количественные значения, на наш взгляд, носит субъективный, если не случайный характер. В нем, например, отсутствуют такие важные для жителей села показатели, как уровень газификации, обеспеченность качественной питьевой водой и др., но введен критерий «доля жителей, которые самостоятельно занимаются физкультурой». Кто и как будет подсчитывать эти цифры - совершенно неясно.

Можно сказать, что пустое бумаготворчество, которое являет нам этот стратегический документ - это вполне безобидно, если бы не создавалась иллюзия, что кто-то успешно трудится, совершенствуется система государственного управления, принимаются серьезные меры, и в результате реализации стратегии все на селе будет в порядке. 
Преобразования регионального и муниципального уровней управления следует рассматривать в рамках общей системы государственного управления Российской Федерации. Можно констатировать, что ее действующая модель сформировалась к началу 2000-х годов и, несмотря на периодическое реформирование, без принципиальных изменений используется до настоящего времени [Аганбегян, 2018; Глазьев, Архипова, 2018; Гринберг, 2018; Ивантер, 2018].

Высокую оценку проводимым реформам системы управления дают только сами реформаторы, экспертное сообщество и широкая общественность отмечают снижение качества управления и образования, качества и доступности медицинских услуг [Глазьев, 2016; Делягин, 2015; Кудрин и др., 2017]. В начале первого десятилетия XXI века, благодаря высоким мировым ценам на топливно-энергетические ресурсы, в России были достигнуты серьезные положительные результаты в социальной сфере, но на развитии экономики регионов и муниципальных образований это практически не отразилось, подавляющее большинство из них по-прежнему целиком и полностью зависят от федерального бюджета. В этом смысле система управления продемонстрировала свою полную беспомощность. То, что она нуждается в радикальных изменениях на всех уровнях - от федерального до муниципального, не вызывает сомнения.

На взгляд авторов, основные направления предлагаемых изменений должны включать следующие пункты.

Необходимо четко определиться с ролью государства в развитии экономики регионов и реализации пространственной стратегии. Если государство намерено переложить ответственность за это на частный бизнес, оно должно разрешить противоречие между экономической ответственностью бизнеса и концентрацией основных финансовых ресурсов в руках государства (в лице Центробанка, федерального бюджета, государственных банков).

На смену модели управления экономикой, в которой главным целевым индикатором является уровень инфляции, должна прийти модель, в которой главным целевым индикатором станет 
рост доходов ${ }^{15}$.Это две противоположные модели с разными приоритетами, последствиями и принципами управления. В последние годы для снижения индекса инфляции в первую очередь оптимизируются (снижаются) государственные расходы (читай - расходы на зарплату работников бюджетной сферы), повышается процентная ставка за кредит. И как результат мы имеем снижение потребительского спроса, отсутствие стимулов к росту производства, экономическую стагнацию во многих регионах и муниципальных образованиях. В модели, ориентированной на рост доходов населения, все происходит в точности наоборот [Абрамовских, Бабенко, 2016; Титов, Широв, 2017].

Мировой опыт показывает, что определяющим фактором эффективности экономического развития и качества жизни населения является институциональная система регионального и муниципального управления, включающая совокупность законодательно-правовых норм, организационных структур и механизмов взаимодействия экономических субъектов, которые определяют контуры среды принятия управленческих решений и обеспечивают достижение целей и направлений социальноэкономического развития регионов Российской Федерации. От того, в какой степени эта система способна представить интересы всех экономических субъектов и насколько адекватно отражает возможности их рационального взаимодействия, зависят непрерывность воспроизводственного процесса и его эффективность - достижение поставленных целей, качество и конкурентоспособность экономики.

Известно, что с переходом к рыночной экономике старая институциональная система, созданная для осуществления директивного управления, не могла выполнять необходимые функции. Вместе с тем, формирование новых управленческих институтов происходит не всегда продуманно, часто они создаются рефлекторно, поэтому через несколько лет, как правило, упраздняются,

\footnotetext{
${ }^{15}$ По данной проблеме в научной экономической литературе существуют различные точки зрения. Академик РАН В.В. Ивантер ключевым индикатором, определяющим рост экономики, считает рост потребительского спроса и инвестиций в реальный сектор экономики, что предполагает стимулирование роста доходов населения и инвестиционной активности [Ивантер и др.,2016]. Эту же точку зрения активно отстаивает академик Р. И. Нигматулин, который на Научно-экспертной сессии «Россия и мир. Российский мировой проект» (26 апреля 2016 г.) выступил с резкой критикой современной экономической политики государства и подчеркнул, что главным фактором роста экономики является потребительский спрос. Следует отметить, что такой подход не нов в мировой экономической науке и практике: именно рост потребительского спроса признается локомотивом роста экономики Китая, Франции и других стран [Научно-экспертная сессия.., 2016].
} 
а на их месте создаются новые институты с новыми названиями. При этом при отсутствии механизма взаимодействия с другими организационными структурами возникает дублирование функций и несогласованность принимаемых решений. Кроме того, не всегда эффективен механизм контроля за использованием бюджетных средств, которые выделяются этим институтам. В связи с этим, наряду с правами и полномочиями институтов регионального управления, должна быть четко определена и их ответственность за результаты деятельности, в противном случае огромные средства государства будут тратиться главным образом на содержание этих институтов.

В современных условиях важную роль в системе регионального и муниципального управления играют планово-прогнозные разработки (концепции, стратегии, программы). Они, прежде всего, отражают разные аспекты экономической политики государства, ее цели, принципы, приоритеты и основные задачи. Проведенный анализ планово-прогнозных разработок на примере стратегии пространственного развития и стратегии устойчивого развития сельских территорий показал, что в этих документах не получили должного внимания многие концептуальные вопросы планирования и управления социально-экономическим развитием на региональном уровне ${ }^{16}$.

Многие проблемы экономического и социального развития регионов вызваны недостаточным учетом пространственного фактора, слабостью территориального планирования и управления, отсутствием специальных органов и механизмов управления пространственным развитием, т.е. отсутствием того, что в совокупности должно составлять институциональную систему управления социально-экономическим развитием регионов.

Проведенное авторами исследование свидетельствует о том, что действующая система управления, ее институты и используемые инструменты не в состоянии обеспечить решение основных задач, определяющих эффективность социально-экономического развития регионов и муниципальных образований. Эти задачи включают, прежде всего, формирование спроса на инновационную продукцию, привлечение инвестиций для производства

\footnotetext{
${ }^{16}$ Материал готовился на основе научной экспертизы проектов стратегий, проведенной авторами по просьбе Законодательного собрания Новосибирской области, и вошел в содержание Заключения, подготовленного Законодательным собранием области для Государственной думы РФ.
} 
наукоемкой продукции и модернизации традиционных отраслей экономики, сбалансированное пространственное развитие страны, обеспечивающее эффективное использование ресурсного потенциала. Дальнейшее промедление с решением этих задач ведет к еще большему технологическому отставанию отечественной экономики и сохранению недопустимой зависимости от развития сырьевого сектора и колебаний спроса и цен на сырье на мировом рынке. Поэтому бесспорной становится острая необходимость изменений в системе государственного и муниципального управления и формирования таких институциональных структур, которые бы адекватно отражали цели социально-экономического развития регионов и муниципальных образований и были бы способны обеспечить их реализацию.

\section{Литература}

Абрамовских Л.Н., Бабенко А.В. К поиску новой модели экономического развития // Экономист. 2016. № 10. С. 34- 42.

Аганбегян А.Г. Почему экономика России топчется на месте? // Проблемы теории и практики управления. 2018. № 3. С. 11-26.

Глазьев С. Ю. В «тысячу первый» раз о выборе между стратегиями социально-экономической деградации страны и современного народнохозяйственного развития // Российский экономический журнал. 2016. № 3. С. 3-17.

Глазьев С.Ю., Архипова В.В. Оценка влияния санкций и других кризисных факторов на состояние российской экономики // Российский экономический журнал. 2018. № 1. С. 3-29.

Гранберг А.Г. О программе фундаментальных исследований пространственного развития России // Регион: экономика и социология. 2009. № 2. С. 166-178.

Гринберг Р.С. Некоторые размышления об императивах экономической модернизации в России // Экономическое возрождение России. 2018. № 2 (56). C. 41-46.

Делягин М.Г. Стратегия модернизации: каким должен быть ответ России глобальной депрессии // Научные труды Вольного экономического общества России. 2015. Т. 196. С. 265-273.

Ивантер В.В., Белкина Т.Д., Белоусов Д.Р. и др. Восстановление экономического роста в России. Научный доклад / Отв. ред. Ивантер В.В. М., 2016. 32 с.

Ивантер В. В. Механизмы экономического роста // Мир новой экономики. 2018. № 3. C. 24-35.

Казакова С.М., Климанов В.В. Зарубежный опыт применения дифференцированного подхода в регулировании регионального развития // Региональная экономика. Юг России. 2018. № 4. С. 55-68.

Кисельников А.А. Подчиненная статистика // Актуальная статистика Сибири. 2017. № 2. С. 46-49. 
Климанов В.В., Ивасько Е.В., Коротких А.М. Практика внедрения территориального подхода в систему государственного управления в российской федерации // Регион: Экономика и социология. 2017. № 1 (93). С. 3-21.

Климанов В.В., Сафина А.И. Вариативность в документах стратегического планирования в стране // Менеджмент и бизнес-администрирование. 2017. № 1. C. 46-65.

Клименко, A.В. Десятилетие административной реформы: результаты и новые вызовы // Вопросы государственного и муниципального управления. 2014. № 1. С. 8-51.

Кудрин А., Горюнов Е., Трунин П. Стимулирующая денежно-кредитная политика: мифы и реальность // Вопросы экономики. 2017. № 5. С. 5-28.

Лексин В.Н. Стратегическое целеполагание в структуре государственного управления // Проблемы теории и практики управления. 2017. № 5. С. 8-20.

Минакир П.А. «Стратегия пространственного развития» в интерьере концепций пространственной организации экономики // Пространственная экономика. 2018. № 4. C. 8-20. DOI: 10.14530/se.2018.4.008-020.

Научно-экспертная сессия «Россия и мир. Российский мировой проект». M., 2016. http://rusrand.ru/public_news/rossiyskiy-mirovoy-proekt-byl-predstavlenv-dome-jurnalistov (дата обращения: 15.12.2018).

Победин А. А. Форум стратегов: новые задачи - новые решения (по итогам XIII общероссийского форума «Стратегическое планирование в регионах и городах России» 27-28 октября 2014 года) // Муниципалитет; экономика и управление. 2014. № 4(9). С. 118-121.

Стратегическое управление региональным и муниципальным развитием / Под ред. А.С. Новоселова, В.Е. Селиверстова. - Новосибирск: ИЭОПП СО PAH, 2018. 496 c.

Титов Б.Ю., Широв А.А. Стратегия роста для России // Вопросы экономики. 2017. № 12. С. 24-39.

Bennett R.J. (ed.) Environment and Planning, Vol. 3, Chapter 1, 'Reflections on "Government and Policy" London, Sage, 2012. 540 pp.

McGrath R.J. The Rise and Fall of Radical Civil Service Reform in the US States // Public Administration Review. 2013. Vol. 73. Iss. 4. Pp. 638-649.

Seltzer E., Carbonell A. Regional Planning in America: Planning Regions // Regional Planning in America: Practice and Prospect, ed. E. Seltzer, A. Carbonell. Cambridge, 2011. Pp. 1-16.

Wolfe D.A. Civic Governance, Social Learning and the Strategic Management of City-Regions // Creating Competitiveness: Entrepreneurship and Innovation Policies for Growth, ed. D. B. Audretsch, M. Lindenstein. Cheltenham, 2013. Pp. 6-25.

Статья поступила 15.03.2019.

Для цитирования: Новоселов А. С., Маршалова А. С. Формирование современной системы регионального и муниципального управления// ЭКО. 2019. № 8. C. 83-102. DOI: 10.30680/ECO0131-7652-2019-7-83-102. 


\section{Summary}

Novoselov, A.S., Doct. Sci. (Econ.), Marshalova, A.S., Cand. Sci. (Econ.), Institute of Economics and Industrial Engineering, SB RAS, Novosibirsk

Formation of a Modern System of Regional and Municipal Governance

Abstract. The article analyzes the existing system of regional and municipal governance to identify the challenges it faces which are beyond its capacity to address. It is noted that the current socio-economic development of Russia is accompanied by a high spatial differentiation of regions and municipalities. Herewith, the regional economic policies and the institutional mechanisms for its implementation do not take into account regional differences, as well as the multistructurality of the economy and a specific role the spatial factor plays in achieving high rates of socio-economic growth. It is shown that over the years the system of management has proved unable to achieve periodically defined strategic goals of development of the Russian economy and its regional policy. The failure of the system of management to reach defined targets is the proof of its inefficiency. To solve these problems, we propose measures to improve the institutional management system, aimed at modernization of the economy, improvement of investment climate, the living standards of municipal populations and the efficiency of regional and municipal governance.

Keywords: Regional and municipal governance; institutional system of governance; spatial differentiation; regional economic policy; economic mechanism; efficiency of governance

\section{References}

Abramovskikh, L.N., Babenko, A.V. (2016). Towards a new model of economic development. Ehkonomist. No.10. Pp. 34-42. (In Russ.).

Aganbegyan, A.G. (2018). Why Does the Russian Economy Make No Headway? Problemy teorii i praktiki upravleniya. No. 3. Pp. 11-26. (In Russ.).

Bennett, R.J. (ed.) (2012). Reflections on "Government and Policy" in Environment and Planning, Vol. 3, Chapter 1, London, Sage. 540 pp.

Delyagin, M.G. (2015). Modernization strategy: how Russia should respond to global depression. Nauchnye trudy Vol'nogo ehkonomicheskogo obshchestva Rossii. Vol. 196. Pp. 265-273. (In Russ.).

Glaz'ev, S. Yu. (2016). “Thousand and One” Times Again on the Choice between Strategies of Socioeconomic Degradation of the Country and Modern National Economic Development. Rossijskij ehkonomicheskij zhurnal. Russian Economic Journal. No. 3. Pp. 3-17. (In Russ.).

Glaz'ev, S. Yu., Arkhipova, V.V. (2018). Sanctions and Other Crisis Factors Impact Assessment on the Russian Economy's State. Rossijskij ehkonomicheskij zhurnal. Russian Economic Journal. No. 1. Pp. 3-29. (In Russ.).

Granberg, A.G. (2009). Conceptual base on the Programme on fundamental issues of spatial development: interdisciplinary aspect issued by the Presidium of the Russian Academy of Sciences. Region: ehkonomika i sociologiya. No.2. Pp. 166-178. (In Russ.).

Grinberg, R.S. (2018). Ruminations on the imperatives of economic modernization in Russia. Ehkonomicheskoe vozrozhdenie Rossii. No. 2 (56). Pp. 41-46. (In Russ.). 
Ivanter, V.V. (2018). Mechanisms of Economic Growth. Mir novoj ehkonomiki. No. 3. Pp. 24-35. (In Russ.).

Ivanter, V.V., Belkina, T.D., Belousov, D.R. (2016). Recovery of economic growth in Russia. Research report. Ed. by Ivanter V.V. Moscow. 32 p. (In Russ.).

Kazakova, S.M., Klimanov, V.V. (2018). Foreign experience of application of the differentiated approach in regulation of regional development. Regional'naya ehkonomika. Yug Rossii. No. 4. Pp. 55-68. (In Russ.).

Kisel'nikov, A.A. (2017). Subordinate statistics. Aktual'naya statistika Sibiri. No. 2. Pp. 46-49. (In Russ.).

Klimanov, V.V., Safina, A.I. (2017). Variability in the strategic planning documents in the country. Menedzhment i biznes-administrirovanie. No. 1. Pp. 46-65. (In Russ.).

Klimanov, V.V., Ivas'ko, E.V., Korotkikh, A.M. (2017). A practice of introducing the territorial approach to the system of public administration in the Russian Federation. Region: Ehkonomika i sociologiya. No. 1 (93). Pp. 3-21. (In Russ.).

Klimenko, A.V. (2014). The decade of administrative reform: results and new challenges. Voprosy gosudarstvennogo i municipal'nogo upravleniya. No. 1. Pp. 8-51. (In Russ.).

Kudrin, A., Goryunov, E., Trunin, P. (2017). Stimulative monetary policy: myths and reality. Voprosy ehkonomikI. No. 5. Pp. 5-28. (In Russ.).

Leksin, V.N. (2017). Strategic goal-setting in state governance structure. Problemy teorii i praktiki upravleniya. No. 5. Pp. 8-20. (In Russ.).

McGrath, R.J. (2013). The Rise and Fall of Radical Civil Service Reform in the US States. Public Administration Review. Vol. 73. Iss. 4. Pp. 638-649.

Minakir, P.A. (2018). "Spatial development strategy": a view from the concepts of spatial organization in the economy. Prostranstvennaya ehkonomika. No. 4. Pp. 8-20. Doi: 10.14530/se.2018.4.008-020.

Nauchno-ehkspertnaya sessiya "Rossiya i mir. Rossijskij mirovoj proekt". Available at: http://rusrand.ru/public_news/rossiyskiy-mirovoy-proekt-bylpredstavlen-v-dome-jurnalistov (accessed 15.12.2018).

Pobedin, A.A. (2014). Forum of the strategists: new challenges - new solutions (following the xiii all-Russian forum "strategic planning in regions and cities Russia” October 27-28, 2014). Municipalitet; ehkonomika i upravlenie. No. 4(9). Pp. 118-121. (In Russ.).

Seltzer, E., Carbonell, A. (2011). Regional Planning in America: Planning Regions. Regional Planning in America: Practice and Prospect, ed. E. Seltzer, A. Carbonell. Cambridge. Pp. 1-16.

Strategic management of regional and municipal development. (2018). Ed. by A. S. Novoselov, V.E. Seliverstov. Novosibirsk, IEOPP SO RAN. 496 p. (In Russ.).

Titov, B. Yu., Shirov, A.A. (2017). Strategy of growth for Russia. Voprosy ehkonomiki. No. 12. Pp. 24-39. (In Russ.).

Wolfe, D.A. (2013). Civic Governance, Social Learning and the Strategic Management of City-Regions in Creating Competitiveness: Entrepreneurship and Innovation Policies for Growth, ed. D. B. Audretsch, M. Lindenstein. Cheltenham. Pp. 6-25.

For citation: Novoselov, A.S., Marshalova, A.S. (2019). Formation of a Modern System of Regional and Municipal Governance. ECO. No. 8. Pp. 83-102. (In Russ.). DOI: 10.30680/ECO0131-7652-2019-7-83-102. 